\title{
Contrast-Enhanced and Time-of-Flight MRA at 3T Compared with DSA for the Follow-Up of Intracranial Aneurysms Treated with the WEB Device
}

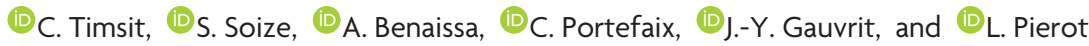

\begin{abstract}
BACKGROUND AND PURPOSE: Imaging follow-up at 3T of intracranial aneurysms treated with the WEB Device has not been evaluated yet. Our aim was to assess the diagnostic accuracy of 3D-time-of-flight MRA and contrast-enhanced MRA at 3T against DSA, as the criterion standard, for the follow-up of aneurysms treated with the Woven EndoBridge (WEB) system.
\end{abstract}

MATERIALS AND METHODS: From June 2011 to December 2014, patients treated with the WEB in our institution, then followed for $\geq 6$ months after treatment by MRA at 3T (3D-TOF-MRA and contrast-enhanced MRA) and DSA within 48 hours were included. Aneurysm occlusion was assessed with a simplified 2-grade scale (adequate occlusion [total occlusion + neck remnant] versus aneurysm remnant). Interobserver and intermodality agreement was evaluated by calculating the linear weighted $\kappa$. MRA test characteristics and predictive values were calculated from a $2 \times 2$ contingency table, by using DSA data as the standard of reference.

RESULTS: Twenty-six patients with 26 WEB-treated aneurysms were included. The interobserver reproducibility was good with DSA ( $\kappa=$ $0.71)$ and contrast-enhanced-MRA ( $\kappa=0.65)$ compared with moderate with 3D-TOF-MRA $(\kappa=0.47)$. Intermodality agreement with DSA was fair with both contrast-enhanced MRA $(\kappa=0.36)$ and 3D-TOF-MRA $(\kappa=0.36)$ for the evaluation of total occlusion. For aneurysm remnant detection, the prevalence was low (15\%), on the basis of DSA, and both MRA techniques showed low sensitivity (25\%), high specificity (100\%), very good positive predictive value (100\%), and very good negative predictive value (88\%).

CONCLUSIONS: Despite acceptable interobserver reproducibility and predictive values, the low sensitivity of contrast-enhanced MRA and 3D-TOF-MRA for aneurysm remnant detection suggests that MRA is a useful screening procedure for WEB-treated aneurysms, but similar to stents and flow diverters, DSA remains the criterion standard for follow-up.

ABBREVIATIONS: $\mathrm{CE}=$ contrast-enhanced; $\mathrm{DL}=$ Dual-Layer; $\mathrm{EV}=$ Enhanced-Visualization; SL $=$ Single-Layer; SLS $=$ Single-Layer Sphere; WEB $=$ Woven EndoBridge

E ndovascular treatment is now the first-line treatment for the management of ruptured and unruptured intracranial aneurysms. ${ }^{1-4}$ However, the limitations of standard coiling for complex aneurysms (large, wide-neck, or developed in a bifurcation) have contributed to the development of new endovascular approaches, including balloon-assisted coiling, stent-assisted coiling, flow diversion, and flow disruption. ${ }^{5}$

The Woven EndoBridge (WEB) aneurysm embolization sys-

Received November 6, 2015; accepted after revision February 28, 2016.

From the Department of Neuroradiology (C.T., S.S., A.B., L.P.), Hôpital Maison Blanche, Université de Champagne-Ardenne, Reims, France; CReSTIC SIC EA3804 (C.P.), Université de Champagne-Ardenne, Reims, France; Department of Neuroradiology (J.-Y.G.), Hôpital Pontchaillou, Rennes, France; and Unité VISAGES U746 INSERM-INRIA (J.-Y.G.), IRISA UMR CNRS 6074, University of Rennes, Rennes,

France.

Please address correspondence to Laurent Pierot, MD, PhD, Department of Diagnostic and Therapeutic Neuroradiology, Maison Blanche Hospital, 45 Rue Cognacq-Jay, Reims 51092, France; e-mail: Ipierot@gmail.com

http://dx.doi.org/10.3174/ajnr.A4791 tem (Sequent Medical, Aliso Viejo, California) is an intrasaccular device designed to disrupt the intra-aneurysmal flow at the level of the neck. ${ }^{6,7}$ Initial experience with the WEB-Dual-Layer (DL) showed the clinical utility of this device in wide-neck bifurcation aneurysms with high technical success and low acute morbidity and mortality. ${ }^{6-16}$ Several WEB devices are now available, including Single-Layer (WEB-SL), Single-Layer Sphere (WEB-SLS), and WEB-DL subtypes. ${ }^{12,13}$ Recently, Enhanced-Visualization (EV) versions were developed to improve fluoroscopic visualization of the devices during treatment.

Because of the potential risk of aneurysm recanalization after endovascular treatment, regular imaging follow-up is recommended. Digital subtraction angiography is the criterion standard for the follow-up of intracranial aneurysms after endovascular treatment but has some disadvantages, including potential neurologic complications, iodinated contrast injection, and radiation exposure. With the goal of avoiding DSA drawbacks, several MR angiography techniques have been tested to follow intracranial 
aneurysms. 3D-TOF-MRA and contrast-enhanced MRA (CEMRA) at 3T are appropriate techniques for the follow-up of coiled aneurysms but have some limitations for the aneurysms treated with stents or flow diverters. ${ }^{17-23}$ Because the WEB is a relatively new device, the value of 3D-TOF-MRA and CE-MRA for the follow-up of WEB-treated intracranial aneurysms has been evaluated in a small number of patients at $1.5 \mathrm{~T} .^{24}$

The aim of this single-center prospective study was to assess the diagnostic accuracy of 3D-TOF-MRA and CE-MRA at 3T against DSA, as the criterion standard, for the evaluation of aneurysm occlusion after WEB treatment.

\section{MATERIALS AND METHODS Study Population}

Institutional review board approval was obtained, and informed consent was waived according to the design of the study. The present study complies with the Standards for Reporting of Diagnostic Accuracy. ${ }^{25}$ Between June 2011 and December 2014, consecutive patients treated at the Universitary Hospital of Reims with the WEB were prospectively included in a data base. Patients treated with the WEB and followed for $\geq 6$ months after treatment with both MRA and DSA were included retrospectively. Additional inclusion criteria were the following: patients older than 18 years of age treated with the WEB; followed with both MRA techniques (3D-TOF-MRA and CE-MRA) at 3T and DSA, with MRA and DSA being performed within $<48$ hours.

To avoid redundant data, in case of multiple MRA or DSA examinations, we used only the last examination.

\section{Imaging Technique for Intra-Arterial DSA}

DSA was performed with a biplane angiographic system (Axiom Artis dBA; Siemens, Erlangen, Germany). Using transfemoral catheterization, we performed selective injections of the internal carotid artery or vertebral artery according to the aneurysm location.

Anteroposterior and lateral working view standard projections were obtained with an additional 3D rotational angiography sequence. For the ICA, $8 \mathrm{~mL}$ of nonionic contrast agent (iodixanol, Visipaque; GE Healthcare, Piscataway, New Jersey) was injected with a velocity of $4 \mathrm{~mL} / \mathrm{s}$. For the vertebral artery, $8-10 \mathrm{~mL}$ was injected with a velocity of $4-5 \mathrm{~mL} / \mathrm{s}$.

\section{Imaging Technique for MRA}

MRA examinations were performed at 3T (Achieva; Philips Healthcare, Best, the Netherlands). Examinations were performed with the following parameters: For 3D-TOF-MRA: TE, $3.45 \mathrm{~ms}$; TR, $18 \mathrm{~ms}$; flip angle, $20^{\circ}$; total acquisition time, 4:59 minutes; number of sections, 140; section thickness, $0.55 \mathrm{~mm}$; FOV, $210 \mathrm{~mm}$; rectangular FOV, 90\%; acquisition matrix, 464; reconstruction matrix, 512; reconstructed voxel size, $0.41 \times$ $0.41 \times 0.55 \mathrm{~mm}$. For the CE-MRA, the parameters were TE, 1.96 $\mathrm{ms}$; TR, $5.4 \mathrm{~ms}$; flip angle, $30^{\circ}$; total acquisition time, 52 seconds; number of sections, 110; section thickness, $0.5 \mathrm{~mm}$; FOV, 210 $\mathrm{mm}$; rectangular FOV, $85 \%$; acquisition matrix, 480 ; reconstruction matrix, 512; reconstructed voxel size, $0.41 \times 0.41 \times 0.50$ $\mathrm{mm}$. CE-MRA randomly sampled the central $k$-space during venous injection of a gadolinium-based contrast agent (gadoterate meglumine, Dotarem; Guerbet, Aulnay-sous-Bois, France). A bolus of $20 \mathrm{~mL}$ was used, followed by $30 \mathrm{~mL}$ of saline with a scopicbased detection of the bolus (phase-contrast survey).

\section{Data Collection}

Clinical and anatomic data regarding the patient (sex, age) and aneurysm (number, localization, size, aneurysm status) were collected. The interval time between aneurysm treatment and anatomic evaluation was also collected. Aneurysm location was classified into 4 groups: anterior cerebral artery/anterior communicating artery, ICA, middle cerebral artery, and posterior circulation/vertebrobasilar artery. We recorded WEB-DL, SL, SLS, and/or EV.

\section{Data Analysis}

All examinations (DSA and MRA) were anonymized by differentnumber random assignment by series. All images were independently evaluated in random order by 2 interventional neuroradiologists (both with $>20$ years' experience). Then, in case of disagreement, consensus was found between the 2 radiologists. DSA, 3D-TOF-MRA, and CE-MRA were evaluated separately without knowledge of the MRA or DSA examination results. The pretreatment DSA was withheld, but the location of the aneurysms to be evaluated was provided to the readers. For both $3 \mathrm{D}$ TOF-MRA and CE-MRA, source images and maximum-intensity-projection reconstructions were analyzed. Aneurysm occlusion was evaluated by using a 3-grade scale (total occlusion, neck remnant, and aneurysm remnant). ${ }^{26}$ A simplified 2-grade scale was used for statistical analysis: adequate occlusion (total occlusion and neck remnant) and aneurysm remnant.

\section{Statistical Analysis}

Quantitative variables are reported as extremes, mean \pm SD, and median (interquartile range), while qualitative variables are reported as number and percentage. The $\kappa$ statistic was used to evaluate interobserver and intermodality agreement for each technique. The interpretation of $\kappa$ was done according to Landis and Koch. ${ }^{27}$ Using the consensus evaluation of intra-arterial DSA as a reference test to evaluate the degree of aneurysm occlusion, we calculated the sensitivity, specificity, negative predictive value, and positive predictive value for 3D-TOF-MRA and CE-MRA. All analyses were performed by using MedCalc for Windows, Version 14.12.0 (MedCalc Software, Mariakerke, Belgium).

\section{RESULTS}

\section{Study Population}

Twenty-six of the 36 patients treated with the WEB were included (age extremes, 34-78 years; mean age, $55 \pm 10$ years; median age, 57 years; interquartile range, $48-61$ years) including 22 women (85\%) and 4 men (15\%). Ten patients were not included for the following reasons: Six did not have DSA follow-up at the time of data collection, 1 died after treatment, and 3 refused MRA followup. The set of imaging data (3D-TOF-MRA, CE-MRA, and DSA) was acquired between 6 and 15 months after the endovascular treatment (mean, $9.2 \pm 3.9$ months; median, 9 months; interquartile range, 6-13 months). Each patient had 1 aneurysm treated with 
the WEB. Detailed characteristics of the aneurysms are shown in Table 1.

Among the aneurysms treated with the WEB, 20 (77\%) were treated with the WEB alone; 5 (19\%), with coils and the WEB; and $1(4 \%)$, with the WEB and a stent. We used WEBs in the following manner: 14 DLs, 8 SLs (including 5 EVs), and 4 SLSs (including 1 $\mathrm{EV})$.

\section{Interobserver Agreement}

When evaluating aneurysm occlusion by using the 3-grade scale, the 2 observers were in agreement in 21 of 26 DSAs (81\%), 21 of 263 D-TOF-MRAs (81\%), and 25 of 26 CE-MRAs $(96 \%)$, resulting in good interobserver agreement for DSA $(\kappa=$ $0.69 ; 95 \%$ CI, 0.46-0.93), excellent agreement for CE-MRA $(\kappa=$ 0.92 ; 95\% CI, $0.76-1.00)$, and moderate agreement for 3D-TOFMRA $(\kappa=0.59 ; 95 \%$ CI, $0.30-0.88)$. When evaluating aneurysm

Table 1: Patient and aneurysm characteristics $(n=26)^{a}$

\begin{tabular}{lc}
\hline \multicolumn{1}{c}{ Patients } \\
\hline Female & $22(84.5 \%)$ \\
Age (yr) & $57(48-61)$ \\
Aneurysms & \\
$\quad$ Aneurysm localization & \\
$\quad$ Internal carotid artery & $6(23 \%)$ \\
$\quad$ Anterior cerebral artery/anterior & $9(35 \%)$ \\
$\quad$ communicating artery & \\
$\quad$ Middle cerebral artery & $7(27 \%)$ \\
$\quad$ Vertebrobasilar artery & $4(15 \%)$ \\
Aneurysm size & \\
$\quad \leq 5 \mathrm{~mm}$ & $1(4 \%)$ \\
$5-10 \mathrm{~mm}$ & $22(84 \%)$ \\
$\quad \geq 10 \mathrm{~mm}$ & $3(12 \%)$ \\
Aneurysm status & \\
$\quad$ Unruptured & $24(92 \%)$ \\
\hline
\end{tabular}

${ }^{a}$ Continuous variables are described as median and interquartile range, and categoric variables, as number and percentage.

Table 2: Aneurysm occlusion evaluation $(n=26)$

\begin{tabular}{lccc}
\hline & $\begin{array}{c}\text { DSA } \\
\text { (No.) (\%) }\end{array}$ & $\begin{array}{c}\text { 3D-TOF-MRA } \\
\text { (No.) (\%) }\end{array}$ & $\begin{array}{c}\text { CE-MRA } \\
\text { (No.) (\%) }\end{array}$ \\
\hline Montreal scale & & & \\
Total occlusion & $12(46)$ & $17(65)$ & $18(69)$ \\
Neck remnant & $10(38.5)$ & $8(31)$ & $7(27)$ \\
Aneurysm remnant & $4(15.5)$ & $1(4)$ & $1(4)$ \\
Simplified 2-grade scale & & & \\
Adequate occlusion & $22(85)$ & $25(96)$ & $25(96)$ \\
Aneurysm remnant & $4(15)$ & $1(4)$ & $1(4)$ \\
\hline
\end{tabular}
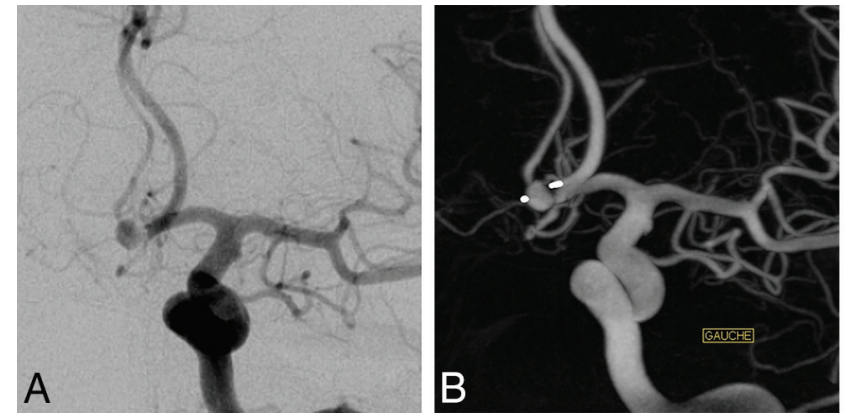

occlusion by using the simplified 2-grade scale (adequate occlusion versus aneurysm remnant), the 2 observers were in agreement in 24 of 26 DSAs (92\%), 24 of 26 3D-TOF-MRAs (92\%), and 25 of 26 CE-MRAs (96\%), resulting in good interobserver agreement for DSA $(\kappa=0.71 ; 95 \%$ CI, $0.32-1.00)$ and CE-MRA $(\kappa=0.65 ; 95 \%$ CI, $0.02-1.00)$ and moderate interobserver agreement for 3D-TOF-MRA ( $\kappa=0.47$; 95\% CI, 0.13-1.00). Despite good raw agreement for all modalities, lower $\kappa$ values were obtained by $3 \mathrm{D}$-TOF by using the 3 -grade occlusion scale and by 3D-TOF and CE-MRA by using the simplified 2-grade scale. This was due to a lower number of aneurysm remnants detected by 3D-TOF-MRA and CE-MRA. Consequently, 1 disagreement for MRA created more imbalance between well-occluded aneurysms versus aneurysm remnants than with DSA, and the corresponding $\kappa$ dropped more.

\section{Intermodality Agreement}

The results of aneurysm occlusion with the Raymond Scale and the simplified 2-grade scale for DSA, 3D-TOF-MRA, and CEMRA are shown in Table 2. After a consensus reading, by using the simplified 2-grade scale, 3D-TOF-MRA and CE-MRA showed identical results. Both MRAs agreed with DSA in 23 of 26 aneurysms (89\%). Disagreement occurred in 3 aneurysm remnants on DSA that were not detected with both MRAs (3 false-negative cases): 2 aneurysm remnants classified as neck remnants from both MRA sequences and 1 aneurysm with complete circulation within the WEB-SL device undetected by both MRAs (Fig 1). 3D-TOF-MRA and CE-MRA showed fair agreement with DSA regarding aneurysm remnant depiction $(\kappa=0.36$; $95 \%$ CI, $-0.16 ; 0.88$, for both techniques).

\section{Diagnostic Accuracies for Aneurysm Remnant Depiction}

With the simplified 2-grade scale for aneurysm-remnant detection, prevalence was low (15\%) on the basis of DSA, and both MRA techniques showed low sensitivity (25\%), high specificity $(100 \%)$, very good positive predictive value (100\%), and very good negative predictive value $(88 \%)$.

\section{Analysis by the Type of WEB}

Among the 14 patients treated with the WEB-DL, with a simplified 2-grade scale, consensus readings agreed for 13 aneurysms (including 12 adequate occlusions and 1 aneurysm remnant) and disagreed for 1 aneurysm remnant on DSA, classified as adequate
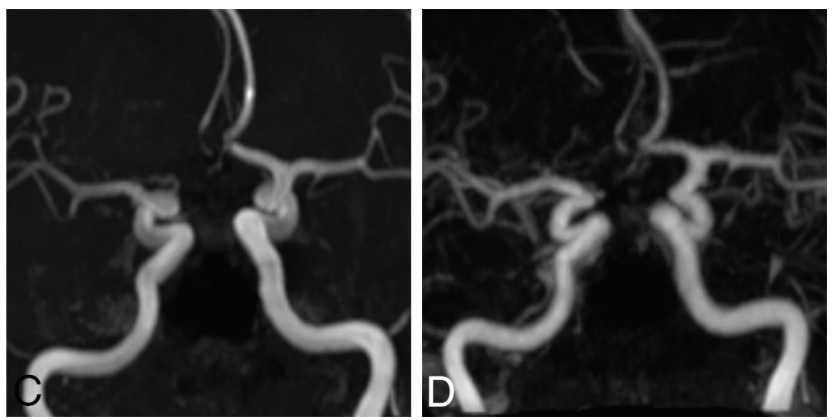

FIG 1. A 78-year-old man with an anterior communicating artery aneurysm treated by the WEB-SL with enhanced visualization. Follow-up images were acquired 7 months after endovascular treatment. 3D-TOF-MRA and CE-MRA were performed 24 hours after DSA. DSA frontal projection $(A)$ and 3D reconstruction in an embolization incidence $(B)$ show aneurysm remnants with complete circulation within the device, while 3D-TOF-MRA and CE-MRA MIP reconstructions ( $C$ and $D)$ show total occlusion. 
occlusion with both MRA techniques. Among the 12 patients treated with the WEB-SL or SLS (including 6 EVs), with the simplified 2-grade scale, consensus readings agreed for 10 aneurysms (4 EVs and 6 non-EVs) and disagreed for 2 aneurysm remnants (2 EVs) on DSA classified as adequate occlusion with both MRA techniques.

\section{DISCUSSION}

In our series of patients with aneurysms treated with the WEB, DSA was superior to CE-MRA and 3D-TOF-MRA for the evaluation of aneurysm remnants, and both MRA techniques had equivalent accuracy $(\kappa=0.36)$; however, the interobserver reproducibility was higher with CE-MRA $(\kappa=0.65)$ than with $3 \mathrm{D}-$ TOF-MRA $(\kappa=0.47)$.

WEB treatment of wide-neck bifurcation aneurysms induces intra-aneurysmal thrombosis. Long-term anatomic results after WEB treatment are available, ${ }^{28,29}$ and several follow-up imaging modalities may be used, such as DSA, MRA, or CTA. If it is now accepted that the artifacts produced by coils do not hamper MRA interpretation, ${ }^{17-21}$ it is important to understand the accuracy and reliability of MRA techniques for WEB-treated aneurysms.

The WEB has a different material composition (nickel-titanium-platinum composite wires with radio-opaque platinum markers) compared with coils but is similar to intracranial stents and flow diverters. Despite recent progress in neurovascular device manufacturing, MR imaging of a stent or flow-diverter lumen remains difficult due to a combination of magnetic susceptibility artifacts and the Faraday cage effect. Given the material similarities to neurovascular stents and flow diverters, the above MR imaging effects may be expected with the WEB.

In terms of magnetic susceptibility, the WEB is similar to most commercially available neurovascular stents and flow diverters that are made from nonferromagnetic alloys such as nitinol with either platinum alloy markers or platinum alloy wires for radioopacity. Of note, a minority of components of these alloys or impurities in the alloy itself are thought to disturb the homogeneity of the magnetic field and cause an alteration of the resonance condition of the protons in the vicinity of the implant, thus leading to intravoxel dephasing with an attendant loss of signal. ${ }^{30}$ These susceptibility artifacts that prevent visualization of the device lumen may be variable, depending on the materials. ${ }^{31}$ This phenomenon may explain, in part, the loss of signal that prevents the physician from seeing the interior of the WEB on MRA sequences. WEBs are now available with composite nitinol/platinum wires that improve radio-opacity but likely have the same magnetic susceptibility profile as intracranial stents and flow diverters with the same or similar materials.

Given that neurovascular stents and flow diverters are constructed of electrically conductive materials, they likely provide a Faraday cage or Faraday shield effect with MR imaging. The braids prevent the proton spins of water molecules in the stent lumen from being flipped or excited. This phenomenon depends on the wave length of the radiation, the size of the mesh in the cage, the conductivity of the materials, thickness, and other variables. ${ }^{32,33}$ Unlike stainless steel or cobalt alloy stents, nitinol stents are relatively more sensitive to radiofrequency artifacts than to susceptibility artifacts. ${ }^{34}$ If one drew a parallel between the WEB and stents/flow diverters of equivalent composition, it seems reasonable that there is also a Faraday shield effect with the WEB and that it contributes to loss of signal from the interior.

The same MRA parameters for stent evaluation were used without optimization for the WEB evaluation. However, it has been shown that optimized sequences can minimize stent-induced artifacts. Using a T1-weighted spin-echo pulse sequence may produce artifacts smaller than those of fast-spoiled gradientrecalled echo pulse sequences, shorter TEs can also decrease stent artifacts, and contrast-enhanced MRA may help to better delineate the stent lumen. ${ }^{30}$ Also, for nitinol stents, the visualization of the stented segment can be at least partially overcome by using a higher flip angle. ${ }^{35-37}$ Recently, a "silent scan" technique combining ultrashort TEs (to minimize the phase dispersion of the labeled blood flow signal in the voxel) and arterial spin-labeling showed promising improvement of flow visualization in an intracranial stent. ${ }^{38}$ This technique may theoretically improve visualization within the WEB device and will deserve further dedicated studies.

There are few data in the literature about noninvasive methods for WEB follow-up. MRA was evaluated in a small number of patients at $1.5 \mathrm{~T}$, while CTA has not been reported. ${ }^{24}$ Mine et $\mathrm{al}^{24}$ compared DSA and CE-MRA for the follow-up of intracranial aneurysms treated with the WEB-DL and found a better intertechnique agreement (mean $\kappa=0.67$ ) than in the present study $(\kappa=0.36)$. Despite these results, $2 / 5(40 \%)$ aneurysm remnants were not detected with CE-MRA in their study, while 3/4 (75\%) were not detected in ours; these findings underlie the sensitivity limitations of MRA compared with DSA for aneurysm remnant.

There are differences between the 2 studies. Mine et $\mathrm{al}^{24}$ evaluated 16 aneurysms treated with the WEB-DL, by using a $1.5 \mathrm{~T}$ device, while we used a $3 \mathrm{~T}$ magnet, which has been reported to be better for the follow-up of coiled intracranial aneurysms ${ }^{20}$ but may have potentially enhanced artifacts. In addition, the time between CE-MRA and DSA was longer in their study (2 months); this difference could have introduced modifications between the 2 examinations. They chose to evaluate only CE-MRA, while our study also provided data on the value of 3D-TOF-MRA. Finally, they classified the occlusion according to the Raymond classification scale, ${ }^{26}$ while we decided to use a simplified 2-grade scale closer to our clinical practice. At first sight, one can infer that there will be more disagreement by using a 3 -grade scale; nevertheless, the 2-grade scale by gathering completely occluded aneurysms and those with neck remnants can influence strongly the intermodality agreement when several disagreements between neck remnant and aneurysm remnant occur. This difference may sometimes be subjective and related to small differences in measurements. Specific occlusion grading scales have been proposed for aneurysms treated with the WEB such as the WEB occlusion scale. The WEB occlusion scale was approved and validated as the grading scale for the 150 patients in the US WEB-IT Clinical Study and was correlated to histology in an 80-subject preclinical study. ${ }^{39,40}$

Our study has several limitations. First, a small number of patients were included. Second, the heterogeneity of endovascular implants (different types of WEB and adjunction, in some cases, of stents or coils) might have affected MRA image quality. Despite 
disagreement occurring in only 1 of the patients with an adjunctive device (WEB +2 coils) and the 2 readers not noticing dramatic modifications between different devices, the adjunctive device may have been the source of supplemental artifacts and remains to be evaluated in a larger series of patients. Third, we used standardized MRA stent parameters, and optimization of these parameters for the WEB may reduce artifacts. Future studies of CTA and optimized MRA for WEB follow-up are necessary. Also, the difference between DSA standard views and strict axial and coronal MIP views for MRA images possibly affected the readers' ratings between the neck and aneurysm remnants, underlying the importance of careful reading of axial source images. ${ }^{23}$

\section{CONCLUSIONS}

In our series, despite acceptable interobserver reproducibility and predictive values, the low sensitivity of CE-MRA and 3D-TOFMRA for aneurysm remnant detection suggests that MRA is a useful screening procedure for WEB-treated aneurysms, but similar to stents and flow diverters, DSA remains the criterion standard for follow-up. Regarding improving noninvasive follow-up of WEB-treated aneurysms, further studies will have to focus on the analysis of optimized MRA techniques in larger cohorts of patients treated with homogeneous WEB devices.

Disclosures: Laurent Pierot-RELATED: Consulting Fee or Honorarium: Sequent Medical; UNRELATED: Consultancy: Blockade Medical, Medtronic, MicroVention, Neuravi.

\section{REFERENCES}

1. Molyneux AJ, Kerr RS, Yu LM, et al; International Subarachnoid Aneurysm Trial (ISAT) Collaborative Group. International Subarachnoid Aneurysm Trial (ISAT) of neurosurgical clipping versus endovascular coiling in 2143 patients with ruptured intracranial aneurysms: a randomised comparison of effects on survival, dependency, seizures, rebleeding, subgroups, and aneurysm occlusion. Lancet 2005;66:809-17 Medline

2. Cognard C, Pierot L, Anxionnat R, et al; Clarity Study Group. Results of embolization used as the first treatment choice in a consecutive nonselected population of ruptured aneurysms: clinical results of the Clarity GDC study. Neurosurgery 2011;69:837-41; discussion 842 CrossRef Medline

3. Pierot L, Spelle L, Vitry F; ATENA Investigators. Immediate clinical outcome of patients harboring unruptured intracranial aneurysms treated by endovascular approach: results of the ATENA study. Stroke 2008;39:2497-504 CrossRef Medline

4. Pierot L, Cognard C, Anxionnat R, et al; CLARITY Investigators. Endovascular treatment of ruptured intracranial aneurysms: factors affecting midterm quality anatomic results-analysis in a prospective, multicenter series of patients (CLARITY). AJNR Am J Neuroradiol 2012;33:1475-80 CrossRef Medline

5. Pierot L, Wakhloo A. Endovascular treatment of intracranial aneurysms: current status. Stroke 2013;44:2046-54 CrossRef Medline

6. Pierot L, Liebig T, Sychra V, et al. Intrasaccular flow-disruption treatment of intracranial aneurysms: preliminary results of a multicenter clinical study. AJNR Am J Neuroradiol 2012;33:1232-38 CrossRef Medline

7. Lubicz B, Mine B, Collignon L, et al. WEB device for endovascular treatment of wide-neck bifurcation aneurysms. AJNR Am J Neuroradiol 2013;34:1209-14 CrossRef Medline

8. Pierot L, Klisch J, Cognard C, et al. Endovascular WEB flow disruption in middle cerebral artery aneurysms: preliminary feasibility, clinical, and anatomical results in a multicenter study. Neurosurgery 2013;73:27-34; discussion 34-35 CrossRef Medline

9. Caroff J, Mihalea C, Dargento F, et al. Woven Endobridge (WEB) Device for endovascular treatment of ruptured intracranial wideneck aneurysms: a single-center experience. Neuroradiology 2014; 56:755-61 CrossRef Medline

10. Lubicz B, Klisch J, Gauvrit JY, et al. WEB-DL endovascular treatment of wide-neck bifurcation aneurysms: short- and midterm results in a European study. AJNR Am J Neuroradiol 2014;35:432-38 CrossRef Medline

11. Papagiannaki C, Spelle L, Januel AC, et al. WEB intrasaccular flow disruptor: prospective, multicenter experience in 83 patients with 85 aneurysms. AJNR Am J Neuroradiol 2014;35:2106-11 CrossRef Medline

12. Pierot L, Moret J, Turjman F, et al. WEB treatment of intracranial aneurysms: feasibility, complications, and 1-month safety results with the WEB DL and WEB SL/SLS in the French Observatory. AJNR Am J Neuroradiol 2015;36:922-27 CrossRef Medline

13. Gherasim DN, Gory B, Sivan-Hoffmann R, et al. Endovascular treatment of wide-neck anterior communicating artery aneurysms using WEB-DL and WEB-SL: short-term results in a multicenter study. AJNR Am J Neuroradiol 2015;36:1150-54 CrossRef Medline

14. Pierot L, Costalat V, Moret J, et al. Safety and efficacy of aneurysm treatment with WEB: results of WEBCAST study. J Neurosurg 2015; 18:1-7 CrossRef Medline

15. Pierot L, Moret J, Turjman F, et al. WEB treatment of intracranial aneurysms: clinical and anatomic results in the French Observatory. AJNR Am J Neuroradiol 2016;37:655-59 CrossRef Medline

16. Pierot L, Spelle L, Molyneux A, et al; WEBCAST and French Observatory Investigators. Clinical and anatomical follow-up in patients with aneurysms treated with WEB device: 1-year follow-up report in the cumulated population of 2 prospective, multicenter series (WEBCAST, French Observatory). Neurosurgery 2016;78:133-41 CrossRef Medline

17. Boulin A, Pierot L. Follow-up of intracranial aneurysms treated with detachable coils: comparison of gadolinium-enhanced 3D time-of-flight MR angiography and digital subtraction angiography. Radiology 2001;219:108-13 CrossRef Medline

18. van Amerongen MJ, Boogaarts HD, de Vries J, et al. MRA versus DSA for follow-up of coiled intracranial aneurysms: a meta-analysis. AJNR Am J Neuroradiol 2014;35:1655-61 CrossRef Medline

19. Pierot L, Portefaix C, Gauvrit JY. Follow-up of coiled intracranial aneurysms: comparison of 3D time-of-flight MR angiography at 3T and 1.5T in a large prospective series. AJNR Am J Neuroradiol 2012; 33:2162-66 CrossRef Medline

20. Pierot L, Portefaix C, Boulin A, et al. Follow-up of coiled intracranial aneurysms: comparison of 3D-time-of-flight and contrast-enhanced magnetic resonance angiography at $3 \mathrm{~T}$ in a large, prospective series. Eur Radiol 2012;22;2255-63 CrossRef Medline

21. Pierot L, Delcourt C, Bouquigny F, et al. Follow-up of intracranial aneurysms selectively treated with coils: prospective evaluation of contrast-enhanced MR angiography. AJNR Am J Neuroradiol 2006; 27:744-49 Medline

22. Agid R, Schaaf M, Farb R. CE-MRA for follow-up of aneurysms post stent-assisted coiling. Interv Neuroradiol 2012;18:275-83 Medline

23. Attali J, Benaissa A, Soize S, et al. Follow-up of intracranial aneurysms treated by flow diverter: comparison of three-dimensional time-of-flight MR angiography (3D-TOF-MRA) and contrast-enhanced MR angiography (CE-MRA) sequences with digital subtraction angiography as the gold standard. J Neurointerv Surg 2016;8: 81-86 CrossRef Medline

24. Mine B, Tancredi I, Aljishi A, et al. Follow-up of intracranial aneurysms treated by a WEB flow disrupter: a comparative study of DSA and contrast-enhanced MR angiography. J Neurointerv Surg 2015 May 21. [Epub ahead of print] CrossRef Medline

25. Bossuyt PM, Reitsma JB, Bruns DE, et al; Standards for Reporting of Diagnostic Accuracy. Towards complete and accurate reporting of 
studies of diagnostic accuracy: the STARD Initiative. Radiology 2003;226:24-28 CrossRef Medline

26. Raymond J, Guilbert F, Weill A, et al. Long-term angiographic recurrences after selective endovascular treatment of aneurysms with detachable coils. Stroke 2003;34:1398-403 CrossRef Medline

27. Landis JR, Koch GG. The measurement of observer agreement for categorical data. Biometrics 1977;33:159-74 CrossRef Medline

28. Pierot L, Klisch J, Liebig T, et al. WEB-DL endovascular treatment of wide-neck bifurcation aneurysms: long-term results in a European series. AJNR Am J Neuroradiol 2015;36:2314-19 CrossRef Medline

29. Sivan-Hoffmann R, Gory B, Riva R, et al. One-year angiographic follow-up after WEB-SL endovascular treatment of wide-neck bifurcation intracranial aneurysms. AJNR Am J Neuroradiol 2015;36: 2320-24 CrossRef Medline

30. Klemm T, Duda S, Machann J, et al. MR imaging in the presence of vascular stents: a systematic assessment of artifacts for various stent orientations, sequence types, and field strengths. J Magn Reson Imaging 2000;12:606-15 Medline

31. Lenhart M, Völk M, Manke C, et al. Stent appearance at contrastenhanced MR angiography: in vitro examination with 14 stents. Radiology 2000;217:173-78 CrossRef Medline

32. Acton QA. Monovalent Cations-Advances in Research and Application. Atlanta: ScholarlyEditions; 2013:407-08

33. Camacho CR, Plewes DB, Henkelman RM. Nonsusceptibility artifacts due to metallic objects in MR imaging. J Magn Reson Imaging 1995;5:75-88 CrossRef Medline
34. Hähnel S, Nguyen-Trong TH, Rohde S, et al. 3.0 Tesla contrast-enhanced MR angiography of carotid artery stents: in vitro measurements as compared with 1.5 Tesla. J Neuroradiol 2006;33:75-80 CrossRef Medline

35. Bartels LW, Bakker CJ, Viergever MA. Improved lumen visualization in metallic vascular implants by reducing RF artifacts. Magn Reson Med 2002;47:171-80 CrossRef Medline

36. Choi JW, Roh HG, Moon WJ, et al. Optimization of MR parameters of 3D-TOF-MRA for various intracranial stents at 3.0T MRI. Neurointervention 2011;6:71-77 CrossRef Medline

37. Meyer JM, Buecker A, Spuentrup E, et al. Improved in-stent magnetic resonance angiography with high flip angle excitation. Invest Radiol 2001;36:677-81 CrossRef Medline

38. Irie R, Suzuki M, Yamamoto M, et al. Assessing blood flow in an intracranial stent: a feasibility study of MR angiography using a silent scan after stent-assisted coil embolization for anterior circulation aneurysms. AJNR Am J Neuroradiol 2015;36:967-70 CrossRef Medline

39. Fiorella D, Arthur A, Byrne J, et al. Interobserver variability in the assessment of aneurysm occlusion with the WEB aneurysm embolization system. J Neurointerv Surg 2015;7:591-95 CrossRef Medline

40. Rouchaud A, Brinjikji W, Ding YH, et al. Evaluation of the angiographic grading scale in aneurysms treated with the WEB device in 80 rabbits: correlation with histologic evaluation. AJNR Am J Neuroradiol 2016;37:324-29 CrossRef Medline 